\title{
Anticoagulant Therapy and Risk of Cerebrovascular Events After Catheter Ablation of Atrial Fibrillation in the Elderly
}

\author{
AURELIE GUIOT, M.D., KRIT JONGNARANGSIN, M.D., AMAN CHUGH, M.D., \\ ARISARA SUWANAGOOL, M.D., RAKESH LATCHAMSETTY, M.D., JAMES D. MYLES, PH.D., \\ QINGMEI JIANG, M.A., M.S., THOMAS CRAWFORD, M.D., ERIC GOOD, D.O., \\ FRANK PELOSI JR, M.D., FRANK BOGUN, M.D., FRED MORADY, M.D., \\ and HAKAN ORAL, M.D.
}

From the Division of Cardiovascular Medicine, University of Michigan, Ann Arbor, Michigan, USA

\begin{abstract}
Stroke and Atrial Fibrillation Ablation. Introduction: Factors associated with cerebrovascular events (CVEs) after radiofrequency catheter ablation (RFA) of atrial fibrillation (AF) have not been well defined in elderly patients ( $\geq 65$ years). The purpose of this study was to determine the prevalence and predictors of CVEs after RFA in patients with AF $\geq 65$ years old, in comparison to patients $<65$ years, and with or without AF.

Methods and Results: This study included 508 consecutive patients $\geq 65$ years old (mean age: $70 \pm 4$ years), who underwent RFA for paroxysmal (297) or persistent (211) AF. A stratified group of 508 patients $<65$ years old who underwent RFA for AF served as a control group. All patients were anticoagulated with warfarin for $\geq 3$ months after RFA. A perioperative CVE ( $\leq 4$ weeks after RFA) occurred in $0.8 \%$ and $1 \%$ of patients $\geq 65$ and $<65$ years old, respectively $(P=1)$. Among the patients $\geq 65$ years old who remained in sinus rhythm after RFA, warfarin was discontinued in $60 \%$ and $56 \%$ of the patients with a $\mathrm{CHADS}_{2}$ score of $\mathrm{O}$ and $\geq 1$, respectively. Paroxysmal AF, no history of CVE, and successful RFA were independent predictors of discontinuing warfarin. During a mean follow-up of $3 \pm 2$ years, a late CVE ( $>4$ weeks after the RFA) occurred in 15 of $508(3 \%)$ of patients $\geq 65$ years old $(1 \%$ per year) and in 5 of $508(1 \%)$ patients $<65$ years old $(0.3 \%$ per year, $P=0.03)$. Among patients $\geq 65$ years old, age $>75$ years old $(O R=4.9, \pm 95 \% C I: 3.3-148.5, P=0.001)$ was the only independent predictor of a CVE. Among patients $<65$ years old, body mass index was the only independent predictor of a late $\mathrm{CVE}(\mathrm{OR}=1.2, \pm 95 \% \mathrm{CI}: 1.03-1.33, \mathrm{P}=0.02)$.

Conclusions: The risk of a periprocedural CVE after RFA of AF is similar among patients $\geq 65$ and $<65$ years old. Late CVEs after RFA are more prevalent in older than younger patients with AF, and age $>75$ years old is the only independent predictor of late CVEs regardless of the rhythm, anticoagulation status, or the CHADS ${ }_{2}$ score (Congestive heart failure, Hypertension, Age $\geq \mathbf{7 5}$ years, Diabetes mellitus and prior Stroke or transient ischemic attack). (J Cardiovasc Electrophysiol, Vol. 23, pp. 36-43, January 2012)
\end{abstract}

atrial fibrillation, catheter ablation, elderly, embolism, stroke

Atrial fibrillation (AF) is associated with a 5- to 6-fold increase in the risk of cerebrovascular events (CVE) and is the leading cause of ischemic strokes. ${ }^{1}$ Although maintenance of sinus rhythm would be expected to restore atrial contractile function and eliminate the propensity for endovascular thrombus formation because of stasis, it has been suggested that patients with AF have intrinsic thrombophilia independent of the rhythm and that AF is a surrogate comorbidity of a systemic disease. ${ }^{2-4}$

Funded in part by a grant from the Leducq Foundation. Dr. Guiot was supported by the French Federation of Cardiology.

Dr. Good participated in research funded by Biotronik. Dr. Oral received research grant from St. Jude Medical and served as a consultant to MedtronicAblation Frontiers. Other authors: No disclosures.

Address for correspondence: Hakan Oral, M.D., Cardiovascular Center, SPC 5853, 1500 E. Medical Center Dr., Ann Arbor, MI 48109-5853, USA. Fax: +734-9367026; E-mail: oralh@umich.edu

Manuscript received 27 March 2011; Revised manuscript received 21 May 2011; Accepted for publication 8 June 2011.

doi: 10.1111/j.1540-8167.2011.02141.x
Anticoagulation with warfarin can have a profound effect on quality of life and is associated with a risk of major bleeding. Therefore, discontinuation of systemic anticoagulation after successful radiofrequency catheter ablation (RFA) of AF bears substantial significance. A prior study suggested that anticoagulation safely can be discontinued after RFA in patients $\leq 65$ years old. ${ }^{5}$ However, it is not clear whether systemic anticoagulation also can be safely discontinued in older patients, who are at higher risk for CVEs. ${ }^{6}$ The purpose of this study was to determine the prevalence and predictors of CVEs after RFA of AF in patients $\geq 65$ years old in comparison to patients $<65$ years old.

\section{Methods}

\section{Study Subjects}

The study included 508 consecutive patients who were $\geq$ 65 years old and underwent RFA to eliminate paroxysmal $(297,58 \%)$ or persistent $\mathrm{AF}(211,42 \%)$ between 2001 and 2009. The mean age was $70 \pm 3$ years (range: $65-83$ years). There were 323 men and 185 women. AF was first diagnosed $6 \pm 6$ years before the presentation. The mean left atrial diameter was $44 \pm 7 \mathrm{~mm}$ and the mean left ventricular ejection fraction was $0.56 \pm 0.08$. Among the 508 patients, 
TABLE 1

Clinical Characteristics

\begin{tabular}{|c|c|c|c|}
\hline & $\begin{array}{c}\text { Patients } \\
\geq 65 \text { years } \\
\text { old }(n=508)\end{array}$ & $\begin{array}{c}\text { Patients } \\
<65 \text { years } \\
\text { old }(n=508)\end{array}$ & P Value \\
\hline Age (years) & $70 \pm 3$ & $53 \pm 9$ & - \\
\hline Paroxysmal AF/persistent AF & $297 / 211$ & $316 / 192$ & 0.25 \\
\hline Gender (male/female) & $323 / 185$ & $405 / 103$ & $<0.001$ \\
\hline Duration of $\mathrm{AF}$ (years) & $6.4 \pm 6.2$ & $5.5 \pm 5.5$ & 0.014 \\
\hline Body mass index $\left(\mathrm{kg} / \mathrm{m}^{2}\right)$ & $29.1 \pm 5.7$ & $31.4 \pm 6.1$ & $<0.001$ \\
\hline Left atrial diameter $(\mathrm{mm})$ & $43.9 \pm 6.6$ & $42.9 \pm 6.7$ & 0.017 \\
\hline Left ventricular ejection fraction & $0.56 \pm 0.08$ & $0.56 \pm 0.09$ & 0.85 \\
\hline Coronary artery disease (\%) & $116(23)$ & $40(8)$ & $<0.001$ \\
\hline Dilated cardiomyopathy (\%) & $10(2)$ & $23(4)$ & 0.021 \\
\hline Prior CVE $(\%)$ & $44(9)$ & $20(4)$ & 0.003 \\
\hline Mean $\mathrm{CHADS}_{2}$ score & $1.1 \pm 0.9$ & $0.7 \pm 0.8$ & $<0.001$ \\
\hline $\mathrm{CHADS}_{2}$ score 0 & $131(26)$ & $234(46)$ & $<0.001$ \\
\hline $\mathrm{CHADS}_{2}$ score 1 & $253(50)$ & $218(43)$ & 0.03 \\
\hline CHADS $_{2}$ score 2 & $86(17)$ & $40(8)$ & $<0.001$ \\
\hline $\mathrm{CHADS}_{2}$ score 3 & $28(6)$ & $16(3)$ & 0.09 \\
\hline $\mathrm{CHADS}_{2}$ score 4 & $10(2)$ & $0(0)$ & 0.002 \\
\hline
\end{tabular}

Continuous variables are expressed as mean \pm SD. Percent values are shown in parentheses.

$\mathrm{AF}=$ atrial fibrillation; $\mathrm{CVE}=$ cerebrovascular event

the $\mathrm{CHADS}_{2}$ score was 0 in 131 (26\%), 1 in 253 (50\%), and $\geq 2$ in 124 patients (24\%; Table 1 ).

A stratified control group consisted of 508 patients who were $<65$ years old and underwent RFA to eliminate paroxysmal (316) or persistent AF (192) within the same period. To account for temporal changes in the ablation technique and duration of follow-up over 9 years, control subjects were chosen as the same number of consecutive patients who underwent RFA in the same monthly intervals as the study subjects during each year of the study. The mean age of the patients in the control group was $53 \pm 9$ years (range: $20-64$ years). The mean $\mathrm{CHADS}_{2}$ score was $1.1 \pm 0.9$ (range: $0-4$ ) and $0.7 \pm 0.8$ (range: $0-3$ ) among patients who were $\geq 65$ and $<65$ years old, respectively $(\mathrm{P}<0.001$; Table 1$)$.

\section{Study Protocol}

The study protocol was approved by the institutional review board. The purpose of this retrospective analysis was to determine the prevalence and predictors of CVEs after RFA in patients with $\mathrm{AF}$ who were $\geq 65$ years old in relation to the anticoagulation status. A stratified group of patients with $\mathrm{AF}$ who were $<65$ years old and who underwent RFA during the same period served as a control group.

To assess the role of RFA in preventing CVEs, 2 hypothetical cohorts were formed based on the Framingham study to serve as additional control groups: (1) otherwise healthy subjects who are $\geq 65$ years old with no history of $\mathrm{AF}^{7}$ and (2) patients $\geq 65$ years old who did not undergo RFA to eliminate $\mathrm{AF}^{1}$

\section{Radiofrequency Catheter Ablation}

All patients underwent left atrial circumferential ablation or antral pulmonary vein isolation. Ablation of complex fractionated atrial electrograms and linear ablation was performed at the discretion of the operator. ${ }^{8,9}$

\section{Anticoagulation Regimen}

A transesophageal echocardiogram was obtained in patients with persistent $\mathrm{AF}$ and in patients with a history of CVE or left atrial appendage thrombus before the procedure. During this study period, warfarin was discontinued 3-5 days before the procedure in all patients and low-molecular-weight heparin (enoxaparin) was administered until the procedure.

During RFA, systemic anticoagulation was achieved with a bolus of intravenous heparin $(100 \mathrm{U} / \mathrm{kg})$ immediately after the transseptal puncture and a continuous infusion of heparin $(\sim 1,000 \mathrm{U} /$ hour$)$ was initiated with intermittent boluses as necessary to maintain the activated clotting time (ACT) at 300-350 seconds. Heparin was discontinued at the conclusion of left atrial ablation, and sheaths were removed once the ACT was $<180$ seconds. Anticoagulation was not reversed unless there was a hemorrhagic emergency.

Three hours after sheath removal, heparin infusion was started at a rate of $1,000 \mathrm{U} /$ hour and was maintained overnight. Warfarin was restarted at the regular maintenance dose on the day of the procedure. Enoxaparin was administrated at $0.5 \mathrm{mg} / \mathrm{kg}$ bid until the international normalized ratio (INR) was $\geq 2$.

After confirming maintenance of sinus rhythm with an autotriggered event monitor $\geq 3$ months after RFA, aspirin, $81-325 \mathrm{mg} /$ day was substituted for warfarin unless there was another indication to continue anticoagulation or a history of CVE. In some cases, the referring physician decided to have the patient continue taking warfarin despite the recommendation to substitute warfarin.

\section{Clinical Follow-Up}

Patients were seen in an outpatient clinic 3 months after the RFA, and every 3-6 months for up to 2 years unless they had recurrent symptoms or atrial arrhythmias. Patients then were periodically monitored and contacted by a nurse. Patients also were instructed to call whenever they had symptoms and were provided with an event monitor. The last follow-up was performed in 2010, in all patients. The mean duration of follow-up was $34 \pm 24$ months and $34 \pm 25$ months in patients $\geq 65$ and $<65$ years old, respectively. A successful RFA was defined as the absence of atrial tachyarrhythmias $>60$ seconds in duration after a 3-month blanking period.

\section{Statistical Analysis}

Continuous variables are expressed as mean \pm standard deviation and were compared with Student's $t$-test or MannWhitney $U$-test as appropriate. Categorical variables were compared by $\chi^{2}$ analysis or Fisher's exact test, as appropriate. ${ }^{2}$ Kaplan-Meier analysis was performed to determine cumulative proportion of patients who remained free from CVEs in each group. Multivariate Cox regression analysis was utilized to identify the predictors of CVEs. A P $<0.05$ indicated statistical significance.

\section{Results}

\section{CVEs Before RFA}

A CVE was reported in 44 of 508 patients (9\%) who were $\geq 65$ years old and 20 of 508 patients (4\%) who were $<65$ years old before the RFA procedure $(\mathrm{P}=0.003)$. 
The prevalence of CVEs before RFA was similar among patients who had paroxysmal or persistent AF, both in patients $\geq 65$ years old $(27 / 297$ [9\%] vs $17 / 211$ [8\%], $\mathrm{P}=0.68)$, and in patients $<65$ years old $(12 / 316[4 \%]$ vs $8 / 192$ [4\%], $\mathrm{P}=0.84$ ), respectively.

\section{Periprocedural CVEs}

A periprocedural CVE ( $\leq 4$ weeks after RFA) occurred in 4 of $508(0.8 \%)$ patients $\geq 65$ years old and in 5 of $508(1 \%)$ patients $<65$ years old at a mean of $6 \pm 5$ days after RFA $(\mathrm{P}=1)$. At the time of the $\mathrm{CVE}$, patients were in $\mathrm{AF}$ or atrial flutter, except for 1 patient who was in sinus rhythm.

In patients $\geq 65$ years old, 1 patient had a TIA (transient ischemic attack, day 4), 2 patients had a stroke (day 0 and 8 ), and 1 patient had an intracranial hemorrhage (day 12). The patient with a TIA had transient slurring of speech. Both patients who suffered from a stroke complained of mild hemiparesis and facial droop, which completely resolved by 10 and 12 months, respectively. A spontaneous intracerebral bleed was discovered on day 12 , in a patient who presented with headache. The international normalized ratio (INR) was $>3$ and the patient recovered after surgical drainage.

In patients $<65$ years old, each of the 5 periprocedural CVEs occurred $\leq 2$ weeks after RFA and was a TIA. Transient aphasia was noticed in 1 patient and visual disturbances in the 4 remaining patients. All patients had a subtherapeutic INR at the time of the CVE; however, 3 of 5 patients were receiving enoxaparin.

Among the patients $\geq 65$ years old, 4 of $4(100 \%)$ and 373 of $504(74 \%)$ who did and did not experience a periprocedural CVE, had $\geq 1 \mathrm{CHADS}_{2}$ risk factor $(\mathrm{P}=0.2)$, whereas in patients $<65$ years old, 2 of $5(40 \%)$ and 272 of 503 (54\%) who did and did not experience a periprocedural CVE had $\geq 1 \mathrm{CHADS}_{2}$ risk factor for stroke $(\mathrm{P}=0.5)$.

\section{Rhythm Status After RFA}

A total of 784 and 787 procedures were performed in the 508 patients $\geq 65$ years old and in the 508 patients $<65$ years old, respectively. At $28 \pm 23$ months after the most recent RFA, among the patients $\geq 65$ years old, 226 of 297 patients (76\%) with paroxysmal AF and 126 of 211 patients $(60 \%)$ with persistent AF were in sinus rhythm, free from atrial tachyarrhythmias. In patients $<65$ years old, 253 of 316 patients (80\%) with paroxysmal AF and 121 of 192 patients (63\%) with persistent $\mathrm{AF}$ were in sinus rhythm.

\section{Discontinuation of Warfarin After RFA}

Warfarin was less likely to be discontinued after RFA in patients $\geq 65$ years old (48\%) than in patients $<65$ years old $(63 \%, \mathrm{P}<0.001)$. Warfarin was discontinued later after the RFA in patients $\geq 65$ years old, $8 \pm 9$ months, than in patients $<65$ years old, $5 \pm 4$ months $(\mathrm{P}<0.001)$.

In patients who remained in sinus rhythm after RFA and had a CHADS 2 score of 0 , warfarin was discontinued in 53 of $89(60 \%)$ and in 121 of $172(70 \%)$ in patients $\geq 65$ and $<65$ years old, respectively $(P=0.10)$. Among the patients who remained in sinus rhythm after RFA and had a $\mathrm{CHADS}_{2}$ score $\geq 1$, warfarin was discontinued in 149 of $264(56 \%)$ and in 148 of $201(74 \%)$ in patients $\geq 65$ and $<65$ years old, respectively $(\mathrm{P}=0.002)$.
TABLE 2

Multivariate Analysis of Predictors of Discontinuation of Warfarin After RFA

\begin{tabular}{lcr}
\hline & $\begin{array}{c}\text { Odds Ratio }(\mathbf{\pm 9 5 \%} \\
\text { Confidence Interval) }\end{array}$ & P Value \\
\hline Patients $\geq 65$ years old & $2.0(1.3-2.9)$ & 0.0006 \\
$\quad$ Paroxysmal AF & $2.3(1.2-4.4)$ & 0.0184 \\
No history of CVE & $3.6(2.4-5.6)$ & $<0.0001$ \\
Successful ablation & $2.6(1.7-3.9)$ & $<0.0001$ \\
Patients $<65$ years old & $13.6(3.8-49.4)$ & $<0.0001$ \\
Paroxysmal AF & $4.1(2.7-6.4)$ & $<0.0001$ \\
No history of CVE & $2.6(1.9-3.3)$ & $<0.0001$ \\
Successful ablation & $0.8(0.6-0.99)$ & 0.04 \\
All patients (n = 1016) & $3.2(1.7-5.8)$ & 0.0002 \\
Paroxysmal AF & $4.8(3.6-6.3)$ & $<0.0001$ \\
Hypertension & No history of CVE & \\
Successful ablation &
\end{tabular}

$\mathrm{AF}=$ atrial fibrillation; $\mathrm{CVE}=$ cerebrovascular event; $\mathrm{RFA}=$ radiofrequency catheter ablation.

\section{Predictors of Discontinuing Warfarin After RFA}

In patients $\geq 65$ years old, among the clinical variables of age $\geq 75$ years old, gender, type of AF, hypertension, diabetes mellitus, congestive heart failure, prior CVE, duration of AF, left atrial size, and maintenance of sinus rhythm after the RFA, paroxysmal AF before RFA (OR $=2.0 ; \pm 95 \%$ CI: $1.3-2.9 ; \mathrm{P}<0.0006)$, no history of CVE $(\mathrm{OR}=2.3 ; \pm 95 \%$ CI: $1.2-4.4 ; \mathrm{P}=0.018)$, and sinus rhythm after the RFA $(\mathrm{OR}=3.6 ; \pm 95 \% \mathrm{CI} ; 2.4-5.6 ; \mathrm{P}<0.0001)$ were independently associated with discontinuation of warfarin after the RFA (Table 2).

In patients $<65$ years old, paroxysmal AF before RFA $(\mathrm{OR}=2.6 ; \pm 95 \%$ CI: 1.7-3.9; P $<0.0001)$, no history of CVE $(\mathrm{OR}=13.6 ; \pm 95 \%$ CI: $3.8-49.4 ; \mathrm{P}<0.0001)$, and sinus rhythm after RFA (OR $=4.1 ; \pm 95 \%$ CI: $2.7-6.4$; $\mathrm{P}<0.0001$ ) were independent predictors of discontinuation of warfarin after the RFA (Table 2).

\section{Late CVEs After RFA}

During a mean follow-up of $34 \pm 24$ months, a late CVE ( $>4$ weeks after RFA) occurred in 15 of 508 patients $(3.0 \%) \geq 65$ years old ( $1 \%$ per year), and in 5 of 508 patients $(1 \%)<65$ years old $(0.3 \%$ per year $)$ after $1.5 \pm 0.8$ procedures, $(\mathrm{P}=0.03)$. CVEs included a TIA in 1 , a stroke in 11 , an intracerebral hemorrhage in 3 patients $\geq 65$ years old, and a TIA in each of the 5 patients $<65$ years old $(\mathrm{P}=0.1$ for TIA, $\mathrm{P}<0.001$ for stroke, and $\mathrm{P}=0.1$ for intracerebral hemorrhage). At the time of the CVE, AF was documented in 11 of $15(73 \%)$ and 2 of $5(40 \%)$ patients $\geq 65$ and $<65$ years old, respectively ( $\mathrm{P}=0.3$ ). During followup, 2 patients died: 1 from an intracerebral hemorrhage and the other from a stroke, 51 days and 7 years after RFA, respectively. In both patients the INR was subtherapeutic (1.2-1.7).

\section{Discontinuation of Warfarin After RFA and CVES}

Among patients $\geq 65$ years old, a CVE occurred in 7 of $242(2.9 \%)$ and in 8 of 266 (3.0\%) in whom warfarin was and was not discontinued after RFA, respectively $(\mathrm{P}=1)$. Among patients $<65$ years old, a CVE occurred in 3 of 319 
$(0.9 \%)$ and in 2 of $189(1.1 \%)$ in whom warfarin was and was not discontinued after the RFA, respectively $(\mathrm{P}=1)$.

\section{CHADS 2 Score and CVEs After RFA}

The mean CHADS $_{2}$ score was $1.2 \pm 1.1$ and $1.1 \pm 0.9$ in patients $\geq 65$ years old who did and did not have a CVE $(\mathrm{P}=0.9)$ and $0.9 \pm 1.0$ and $0.7 \pm 0.8$ in patients $<65$ years old who did and did not have a CVE after the RFA $(\mathrm{P}=0.5)$.

Among patients $\geq 65$ years old, 13 of $15(87 \%)$ and 366 of 493 patients $(74 \%)$ who did and did not experience a late CVE had a $\mathrm{CHADS}_{2}$ score $\geq 1(\mathrm{P}=0.4)$, whereas in patients $<65$ years old, 4 of $5(80 \%)$ and 270 of 503 patients (54\%) who did and did not experience a late CVE had a $\mathrm{CHADS}_{2}$ score $\geq 1(\mathrm{P}=0.2)$.

\section{$\mathrm{CHADS}_{2}$ Score, Discontinuation of Warfarin and CVE}

Among patients $\geq 65$ years old, warfarin was discontinued in 199 of 377 patients (53\%) who had a CHADS score $\geq 1_{1}$ and in 63 of 131 patients (48\%) who had a CHADS 2 score of $0(\mathrm{P}=0.4)$. A CVE occurred in 13 of 377 patients $(3 \%)$ who had a CHADS 2 score $\geq 1$ and in 2 of 131 patients ( $2 \%$ ) who had a $\mathrm{CHADS}_{2}$ score of $0(\mathrm{P}=0.4)$. After a successful procedure, the risk of CVE was similar between patients who had a CHADS ${ }_{2}$ score $\geq 1$ and were on warfarin $(4 / 115,3 \%)$ and patients who had a $\mathrm{CHADS}_{2}$ score of 0 and were off warfarin $(0 / 53, \mathrm{P}=0.3)$.

\section{Predictors of CVEs After RFA}

In patients $\geq 65$ years old, among the clinical variables of age, gender, AF type, left atrial size, body mass index (BMI), AF duration, diabetes mellitus, hypertension, coronary artery disease, dilated cardiomyopathy, left ventricular ejection fraction, $\mathrm{CHADS}_{2}$ score, prior CVE, successful ablation, and discontinuation of warfarin therapy, the only independent predictor of CVEs was age $>75$ years old $(\mathrm{OR}=4.9 ; \pm 95 \% \mathrm{CI}: 1.7-14.5 ; \mathrm{P}=0.004$ for all CVEs and $\mathrm{OR}=7.0 ; \pm 95 \%$ CI: $2.3-21.6 ; \mathrm{P}=0.0008$ for late CVEs; Table 3). Age was also an independent predictor of CVEs when analyzed as a continuous variable $(\mathrm{OR}=7.9 ; \pm 95 \%$ CI: $2.5-25.2 ; \mathrm{P}=0.0004)$.

Among patients $\geq 65$ years old who maintained sinus rhythm after the RFA and who had discontinued warfarin $(n=202)$, age $>75$ years old was also the only predictor of CVEs (OR $=21.2 ; \pm 95 \%$ CI: $3.3-138.5 ; \mathrm{P}=0.0014$; Table 4).

In patients $<65$ years old, there were no independent predictors of CVEs during or after the RFA. However, BMI was identified as an independent predictor of CVEs that occurred $>4$ weeks after the RFA $(\mathrm{OR}=1.2 ; \pm 95 \%$ CI: 1.03-1.33; $\mathrm{P}=0.015$; Table 3). Anticoagulation status and $\mathrm{CHADS}_{2}$ score were not predictive of a CVE in any model (Table 3).

\section{Intracranial Hemorrhage}

An intracranial hemorrhage occurred in 4 of 1016 patients $(0.4 \%)$ and consisted of a subdural hematoma after a fall (INR $=1.6)$ that resolved after discontinuation of warfarin, a cerebellar hemorrhage (INR $=3.7$ ) with recovery after reversal of anticoagulation, an intracerebral bleed (INR $>3$ ) that resolved after neurosurgery, and an intracerebral bleed
TABLE 3

Multivariate Analysis of Predictors of CVEs After RFA of AF

\begin{tabular}{|c|c|c|}
\hline & $\begin{array}{l}\text { Odds Ratio ( } \pm 95 \% \\
\text { Confidence Interval) }\end{array}$ & $P$ Value \\
\hline \multicolumn{3}{|l|}{$\begin{array}{l}\text { Patients } \geq 65 \text { years old } \\
\text { All CVEs }\end{array}$} \\
\hline $\begin{array}{l}\text { Age }>75 \text { years old } \\
\text { Late }(>4 \text { weeks }) \text { CVEs }\end{array}$ & $4.9(1.7-14.5)$ & 0.004 \\
\hline Age $>75$ years old & $7.0(2.3-21.6)$ & 0.0008 \\
\hline $\begin{array}{l}\text { Patients }<65 \text { years old } \\
\text { All CVEs } \\
\text { Late CVEs }\end{array}$ & No predictors & \\
\hline BMI & $1.2(1.03-1.33)$ & 0.015 \\
\hline $\begin{array}{l}\text { All Patients } \\
\text { All CVEs }\end{array}$ & & \\
\hline Age $>75$ years old & $6.0(2.1-17.1)$ & 0.0007 \\
\hline $\begin{array}{l}\text { Diabetes mellitus } \\
\text { Late CVEs }\end{array}$ & $2.5(1.02-6.2)$ & 0.044 \\
\hline Age $>75$ years old & $9.7(3.3-28.4)$ & $<0.0001$ \\
\hline
\end{tabular}

$\mathrm{AF}=$ atrial fibrillation; $\mathrm{BMI}=$ body mass index $\mathrm{CVE}=$ cerebrovascular event; RFA= radiofrequency catheter ablation.

(INR $=1.7)$ that was fatal. All patients were $\geq 65$ years old and were in $\operatorname{AF}(n=3)$ or in atrial flutter $(n=1)$.

\section{Risk of CVE}

During a mean follow-up of $3 \pm 2$ years old, the cumulative proportion of patients who remained free from any CVE (periprocedural or late CVE) after RFA was $96.3 \%$ in patients $\geq 65$ years old and $98 \%$ in patients $<65$ years old, respectively ( $\mathrm{P}=0.095$; Fig. 1$)$. The proportion of patients who remained free from a late CVE was $97 \%$ in patients $\geq 65$ years old and $99 \%$ in patients $<65$ years old, respectively ( $\mathrm{P}=0.024$; Fig. 2).

Among patients who had a successful outcome after RFA of $\mathrm{AF}$ and who were no longer receiving warfarin, 198 of $202(98 \%)$ patients $\geq 65$ years old $(0.7 \%$ risk of CVE per year) and 266 of $269(98.8 \%)$, patients $<65$ years old $(0.4 \%$ risk of CVE per year) were free from late CVEs $(\mathrm{P}=0.70$; Fig. 3).

The expected cumulative freedom from a CVE in a hypothetical cohort of human subjects $\geq 65$ years old was 98.2\% among those with no history of $\mathrm{AF}$ and $95.9 \%$ among those with AF who did not undergone RFA of the AF (Fig. 3).

\section{TABLE 4}

Multivariate Analysis of Predictors of Late CVEs in Patients Who Discontinued Warfarin After Successful RFA of AF

\begin{tabular}{lcc}
\hline & $\begin{array}{c}\text { Odds Ratio }( \pm 95 \% \\
\text { Confidence Interval) }\end{array}$ & P Value \\
\hline Patients $\geq 65$ years old $(\mathrm{n}=202)$ & $21.2(3.3-138.5)$ & 0.0014 \\
$\quad$ Age $>75$ years old & & \\
Patients $<65$ years old $(\mathrm{n}=269)$ & $8.8(7.0-13.0)$ & 0.054 \\
CHADS score $_{2} 1$ & No predictors & \\
All patients $(\mathrm{n}=471)$ &
\end{tabular}

CVE $=$ cerebrovascular event. 


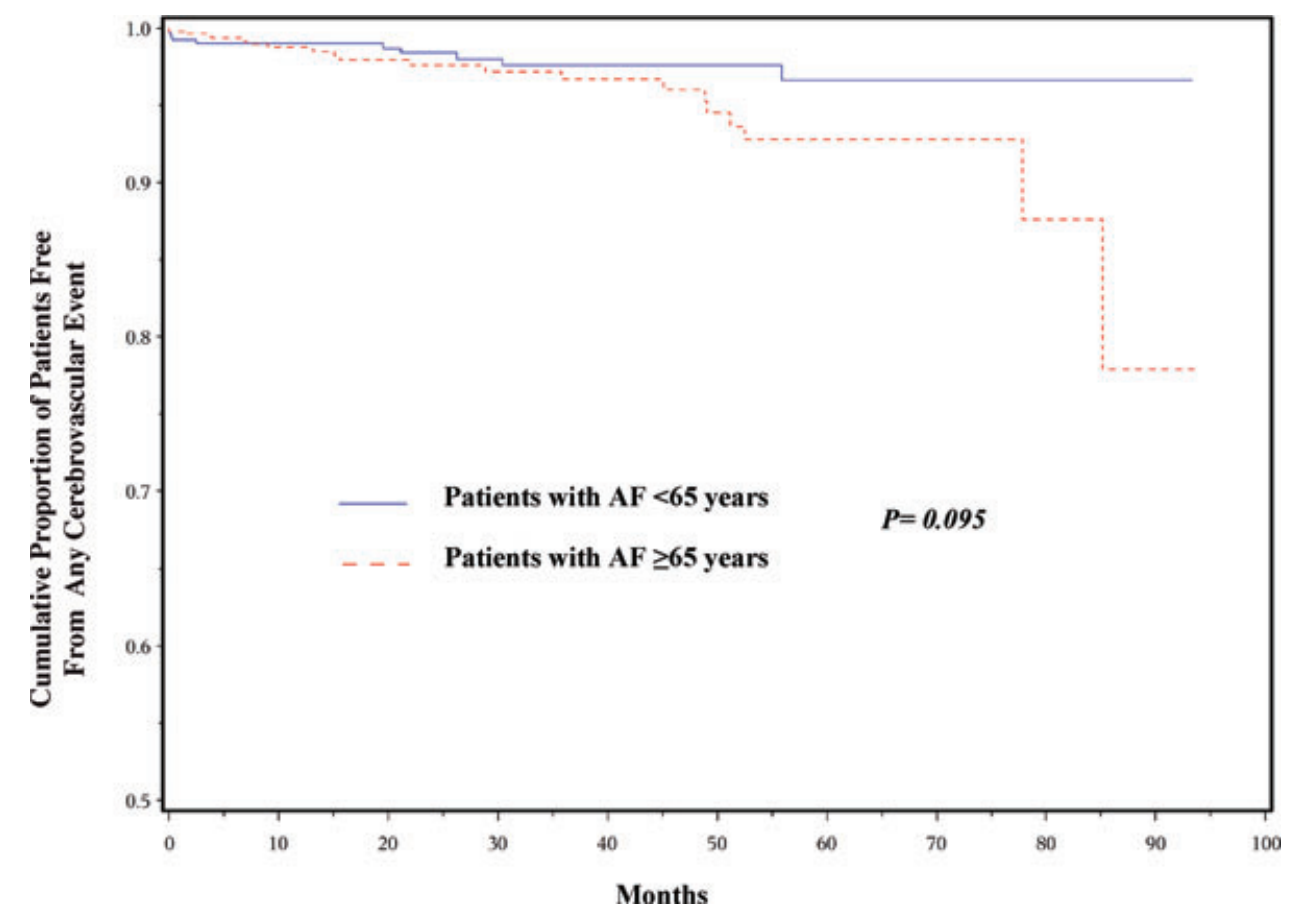

Figure 1. Freedom from any CVE after RFA of AF. On an intention-to-treat analysis, during a mean follow-up of $3 \pm 2$ years, cumulative proportion of patients $\geq 65$ years old (red dotted line) who remained free from any CVE after RFA of AF was similar to patients $<65$ years old (blue line, $P=0.095$, log-rank test).

\section{Discussion}

\section{Main Findings}

The main findings of this study are: (1) a periprocedural CVE may occur in $\sim 1 \%$ of patients after RFA of AF, usually within 2 weeks of the procedure and has a similar preva- lence in patients $\geq 65$ and $<65$ years old; (2) warfarin is discontinued sooner and in a higher proportion of patients $<$ 65 years old than $\geq 65$ years old after RFA, despite similar efficacy; (3) warfarin is more likely to be discontinued after RFA in patients with paroxysmal AF, no history of a CVE, and freedom from AF regardless of age; (4) the incidence

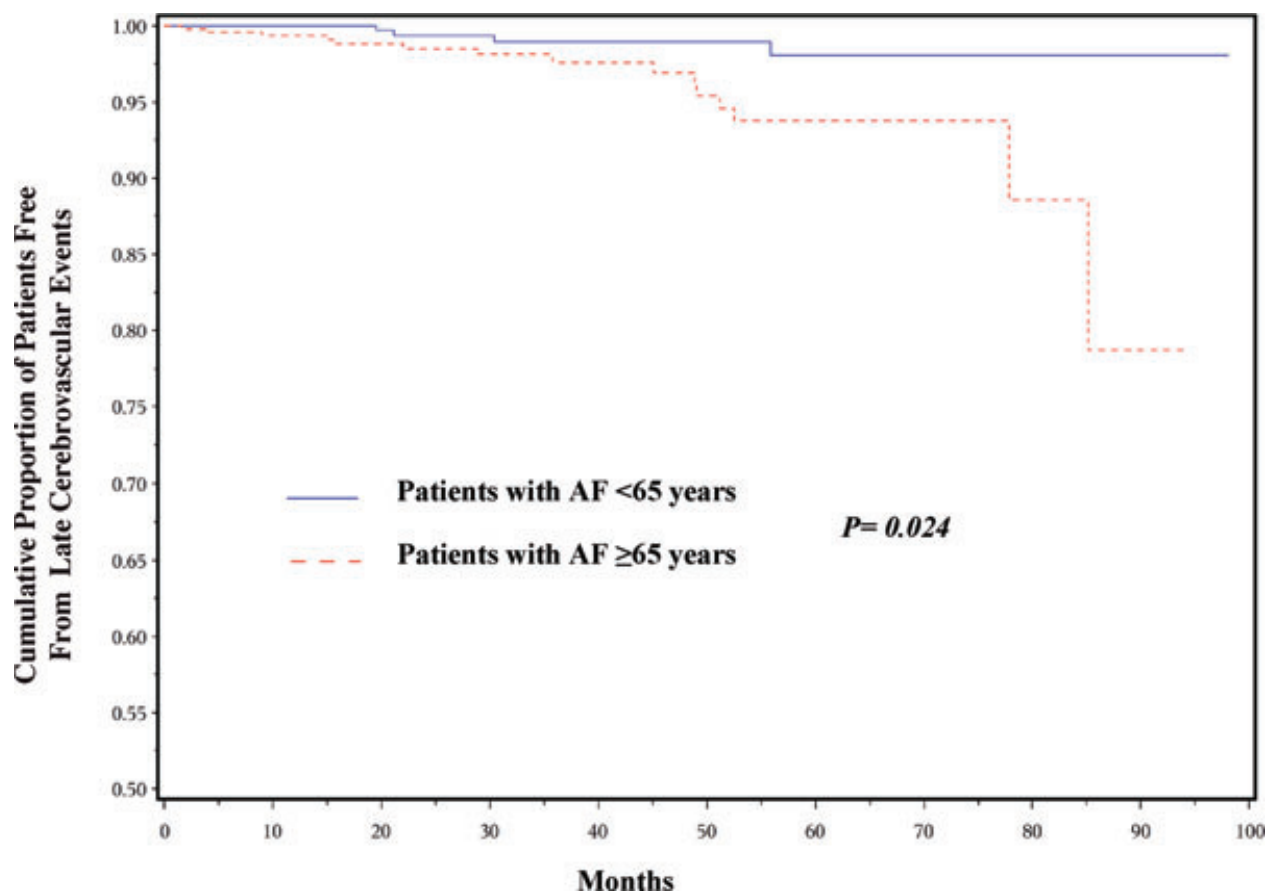

Figure 2. Freedom from late CVEs after RFA of AF. On an intention-to-treat analysis, patients $\geq 65$ years old (red dotted line) were more likely to have late CVEs ( $>4$ weeks) after RFA of AF than patients $<65$ years old (blue line, $P=0.024$, log-rank test). 
of a late CVE after RFA is higher in patients $\geq 65$ years old ( $1 \%$ per year) than in patients $<65$ years old $(0.3 \%$ per year); (5) in patients $\geq 65$ years old, age $>75$ years old is the only predictor of CVEs after RFA, whereas in patients $<65$ years old, a higher BMI is associated with late CVEs; (6) warfarin therapy and $\mathrm{CHADS}_{2}$ score are not predictive of CVEs after RFA of AF, regardless of age; and (7) among patients $\geq 65$ years old, at 3 years after RFA, cumulative freedom from any CVE is $98 \%$ in patients who discontinue warfarin after successful RFA of AF compared to $96 \%$ in patients with AF who do not undergo RFA, and $98 \%$ in otherwise healthy subjects with no history of AF.

\section{Periprocedural CVEs}

Periprocedural CVEs occurred in $\sim 1 \%$ of patients during and early after RFA regardless of age. The technique of RFA, ablation technology, and the periprocedural anticoagulation regimen rather than preexisting conditions are likely to play an important role in periprocedural CVEs. Therefore, age by itself should not be a concern as far as the risk of periprocedural CVEs is considered.

Periprocedural CVEs were most prevalent early after RFA, a period when anticoagulation may have been subtherapeutic because of bridging with LMWH during reinitiation of warfarin therapy. ${ }^{5}$ However, as the recently proposed approach of performing RFA without discontinuing warfarin is more widely adopted and the ablation technologies are more refined, the prevalence of periprocedural CVEs is likely to decrease. ${ }^{10}$

\section{Late CVEs}

A CVE was reported in $0.5-7 \%$ of patients after RFA of AF in prior studies. ${ }^{5,11,12}$ However, the effect of age on the risk of CVEs has not been systematically analyzed. In this study, the risk of a CVE was significantly higher, $1 \%$ per year, in patients $\geq 65$ years old than in patients $<65$ years old, $0.3 \%$ per year, after RFA of AF. Similar to the findings of a prior study, the incidence of late CVEs was low ( $0.2 \%$ per year) in patients $<65$ years old who remained in sinus rhythm and discontinued warfarin after successful RFA. ${ }^{5}$ The incidence of a late CVE was $0.7 \%$ per year in patients $\geq 65$ years old who discontinued warfarin after successful ablation in this study and appears to be lower than the incidence of $2.3 \%$ per year of CVEs reported in a recent analysis of stroke risk in patients with AF. ${ }^{13}$

The only independent predictor of CVEs in patients $\geq 65$ years old was age $>75$ years old regardless of the rhythm, anticoagulation status, or the $\mathrm{CHADS}_{2}$ score. There are several possible explanations for this observation: (1) age-related comorbidities such as hypertension, vascular disease, and senile degenerative changes such that elimination of AF does not eliminate the risk of CVEs; (2) asymptomatic recurrences of AF that were not detected during follow-up. However, asymptomatic recurrences of AF are not known to be more prevalent in older than in younger patients; (3) the anticoagulant effects of warfarin may not have been sufficient to completely eliminate thrombus formation in all patients with AF. Furthermore, warfarin is associated with a risk of intracranial bleeding, which may negate the beneficial effects particularly in low- and intermediate-risk patients; and (4)

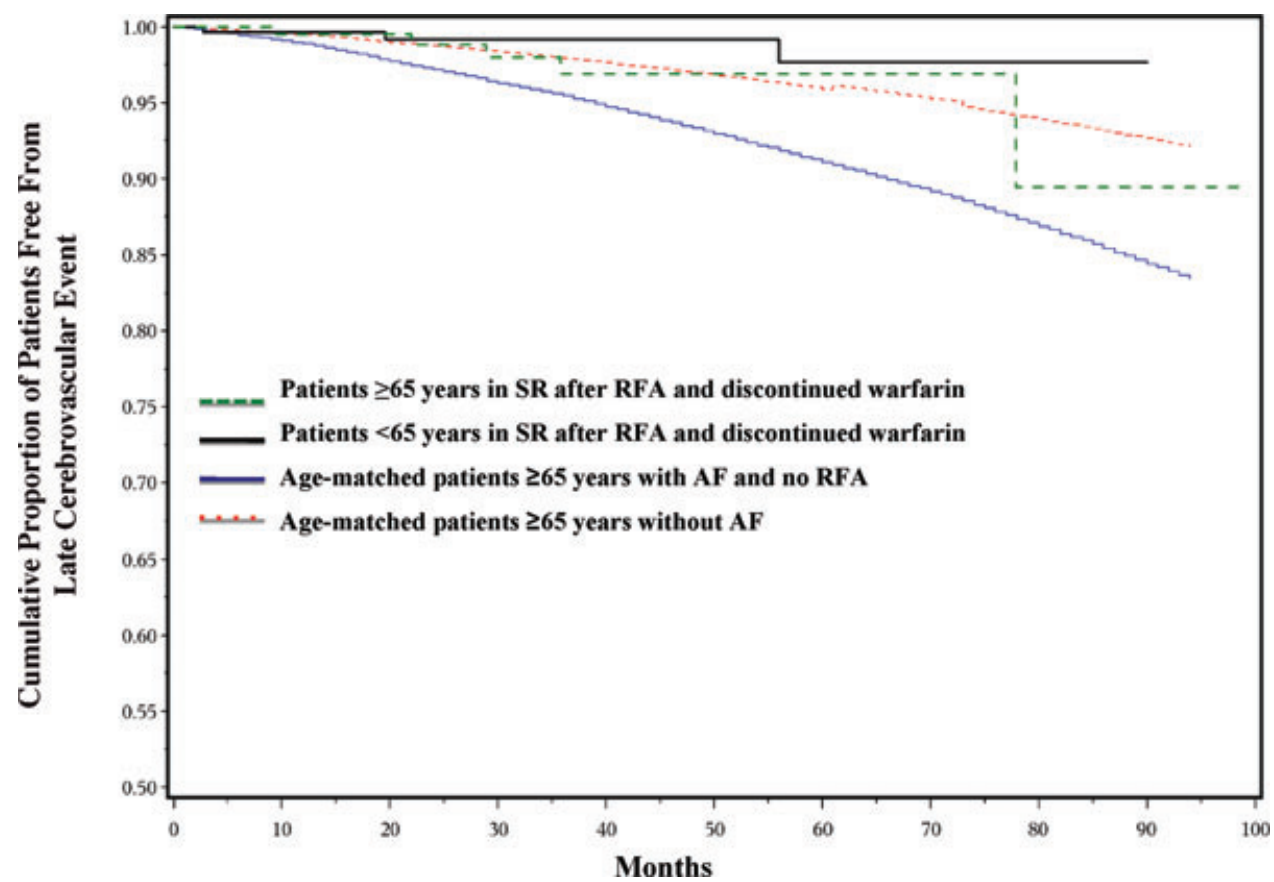

Figure 3. Freedom from late CVEs after discontinuation of warfarin. At 33 months, freedom from late CVEs is shown in patients: (1) with AF and $\geq 65$ years old after successful RFA and discontinuing warfarin (green dotted line); (2) with AF and $<65$ years old after successful RFA and discontinuing warfarin (black line); (3) with AF and $\geq 65$ years old who had not undergone RFA for AF (red dotted line); and (4) without AF and $\geq 65$ years old (blue line). SR $=$ sinus rhythm. 
RFA has been shown to result in a $\geq 30 \%$ decrease in left atrial contractile and transport function. Older patients may have a greater degree of preexisting left atrial fibrosis, such that further declines in left atrial contractile function because of RFA may lead to a clinically significant compromise in left atrial transport function. It should be noted that age remains as an independent predictor of late CVEs when analyzed as a continuous variable. Because aging is a dynamic process, it may be more helpful to consider age as a continuum in assessing the risk of CVEs rather than as a discrete threshold value in risk prediction models.

Consistent with the prior reports on association between high BMI and risk of stroke, ${ }^{14-16}$ BMI was indentified as an independent predictor of late CVEs in patients $<65$ years old after RFA of AF in this study. The mechanisms by which BMI increases the risk of CVEs appear to be multifactorial and may include, behavioral and social habits, alterations in plasminogen activator inhibitor and fibrinolytic activity, an increase in cardiac workload and stroke volume, and changes in glucose and lipid metabolism.

\section{Prior Studies}

In a prior study of 755 patients with paroxysmal or persistent $\mathrm{AF}^{5}{ }^{5}$ discontinuation of anticoagulant therapy with warfarin was found to be safe except in patients who had a prior stroke or who were $>65$ years old.

In another study, clinical outcomes after ablation of complex fractionated atrial electrograms were assessed in 674 patients $(40 \%$ with paroxysmal $\mathrm{AF})>65$ years old who had $\geq$ 1 risk factor for stroke. ${ }^{12}$ Ablation was performed with a 4 or 8-mm nonirrigated tip catheter. Sinus rhythm was maintained in $81 \%$ of the patients during a mean follow-up of 2 years. The mortality rate was higher in patients with recurrent AF than in patients who remained in sinus rhythm after RFA. Age was an independent predictor of mortality. Warfarin was discontinued in $84 \%$ of the patients. There were a total of 11 CVEs: 5 in patients who discontinued warfarin and 6 in patients who continued warfarin. The 5-year stroke rate was $3 \%$ versus $23 \%$ in patients who discontinued warfarin and who remained on warfarin, respectively. However, unlike in the present study, there was no control group in the prior study. Because outcomes after RFA were assessed primarily by clinical symptoms and asymptomatic recurrences may not have been adequately captured, the CVE rate was relatively low in this high-risk group of patients in the prior study.

\section{Limitations}

A limitation of this study is that it is an observational study without prospective randomization of patients to anticoagulant therapy after RFA. However, in the absence of supportive data, discontinuation of warfarin after RFA in high-risk patients would not be feasible.

A second limitation is that despite a large cohort of patients $\geq 65$ years old who underwent RFA to eliminate AF, the event rate was relatively low. Therefore, the study may have been underpowered to identify all predictors of CVEs after RFA.

A third limitation is that the mean duration of follow-up was 3 years. Therefore, it may not be possible to predict the long-term risk of CVEs in an aging population particu- larly when age is a significant predictor of CVEs. However, the data presented in this study were acquired over a 9-year period. Another limitation may be that ablation techniques and technologies have evolved during the study period. However, there were no temporal trends in the risk of CVEs in this study.

To provide an estimate of the CVE rates in age-matched human subjects with and without AF, comparisons were made to hypothetical cohorts of patients based on the Framingham study. However, these historical event rates may not be representative of current event rates on contemporary therapy.

Finally, the findings of this study apply to patients receiving anticoagulant therapy with warfarin. Whether the newer oral anticoagulants will be more effective than warfarin in preventing CVEs in the elderly remains to be determined. However, because of a variety of factors, particularly cost, warfarin is likely to remain widely used in a large proportion of patients with AF.

\section{Clinical Implications}

The efficacy of RFA and the risk of periprocedural CVEs appear to be similar in older and younger patients with AF, therefore age should not be a criterion in estimating the risk of stroke in patients contemplating an RFA procedure for AF.

Age $>75$ is the only predictor of CVEs after RFA of AF in patients $\geq 65$ years old, suggesting that the risk of CVEs in older patients is because of mechanisms other than recurrent $\mathrm{AF}$ or anticoagulation status. It remains to be determined whether new oral antithrombin inhibitors or obliteration of the left atrial appendage will lead to a decrease in CVEs in elderly patients with AF.

\section{References}

1. Wolf PA, Abbott RD, Kannel WB: Atrial fibrillation as an independent risk factor for stroke: The Framingham Study. Stroke 1991;22:983-988.

2. Lip GY: Does atrial fibrillation confer a hypercoagulable state? Lancet 1995;346:1313-1314.

3. Lip GY, Lip PL, Zarifis J, Watson RD, Bareford D, Lowe GD, Beevers DG: Fibrin D-dimer and beta-thromboglobulin as markers of thrombogenesis and platelet activation in atrial fibrillation. Effects of introducing ultra-low-dose warfarin and aspirin. Circulation 1996;94:425-431.

4. Lip GY, Patel JV, Hughes E, Hart RG: High-sensitivity C-reactive protein and soluble CD40 ligand as indices of inflammation and platelet activation in 880 patients with nonvalvular atrial fibrillation: Relationship to stroke risk factors, stroke risk stratification schema, and prognosis. Stroke2007;38:1229-1237.

5. Oral H, Chugh A, Ozaydin M, Good E, Fortino J, Sankaran S, Reich S, Igic P, Elmouchi D, Tschopp D, Wimmer A, Dey S, Crawford T, Pelosi F Jr, Jongnarangsin K, Bogun F, Morady F: Risk of thromboembolic events after percutaneous left atrial radiofrequency ablation of atrial fibrillation. Circulation 2006;114:759-765.

6. Fuster V, Ryden LE, Cannom DS, Crijns HJ, Curtis AB, Ellenbogen KA, Halperin JL, Le Heuzey JY, Kay GN, Lowe JE, Olsson SB, Prystowsky EN, Tamargo JL, Wann S, Smith SC Jr., Jacobs AK, Adams CD, Anderson JL, Antman EM, Halperin JL, Hunt SA, Nishimura R, Ornato JP, Page RL, Riegel B, Priori SG, Blanc JJ, Budaj A, Camm AJ, Dean V, Deckers JW, Despres C, Dickstein K, Lekakis J, McGregor K, Metra M, Morais J, Osterspey A, Tamargo JL, Zamorano JL: ACC/AHA/ESC 2006 Guidelines for the Management of Patients with Atrial Fibrillation: A report of the American College of Cardiology/American Heart Association Task Force on Practice Guidelines and the European Society of Cardiology Committee for Practice Guidelines (Writing Committee to Revise the 2001 Guidelines for the Management of Patients With Atrial Fibrillation): Developed in collaboration with the European Heart Rhythm Association and the Heart Rhythm Society. Circulation 2006;114:e257-354. 
7. Wolf PA, D'Agostino RB, Belanger AJ, Kannel WB: Probability of stroke: A risk profile from the Framingham Study. Stroke 1991;22:312318.

8. Oral H, Chugh A, Yoshida K, Sarrazin JF, Kuhne M, Crawford T, Chalfoun N, Wells D, Boonyapisit W, Veerareddy S, Billakanty S, Wong WS, Good E, Jongnarangsin K, Pelosi F Jr, Bogun F, Morady F: A randomized assessment of the incremental role of ablation of complex fractionated atrial electrograms after antral pulmonary vein isolation for long-lasting persistent atrial fibrillation. J Am Coll Cardiol 2009;53:782-789.

9. Oral H, Pappone C, Chugh A, Good E, Bogun F, Pelosi F Jr, Bates ER, Lehmann MH, Vicedomini G, Augello G, Agricola E, Sala S, Santinelli V, Morady F: Circumferential pulmonary-vein ablation for chronic atrial fibrillation. N Engl J Med 2006;354:934-941.

10. Wazni OM, Beheiry S, Fahmy T, Barrett C, Hao S, Patel D, Di Biase L, Martin DO, Kanj M, Arruda M, Cummings J, Schweikert R, Saliba W, Natale A: Atrial fibrillation ablation in patients with therapeutic international normalized ratio: Comparison of strategies of anticoagulation management in the periprocedural period. Circulation 2007;116:25312534.
11. Cappato R, Calkins H, Chen SA, Davies W, Iesaka Y, Kalman J, Kim YH, Klein G, Packer D, Skanes A: Worldwide survey on the methods, efficacy, and safety of catheter ablation for human atrial fibrillation. Circulation 2005;111:1100-1105.

12. Nademanee K, Schwab MC, Kosar EM, Karwecki M, Moran MD, Visessook N, Michael AD, Ngarmukos T: Clinical outcomes of catheter substrate ablation for high-risk patients with atrial fibrillation. J Am Coll Cardiol2008;51:843-849.

13. Menke J, Luthje L, Kastrup A, Larsen J: Thromboembolism in atrial fibrillation. Am J Cardiol 2010;105:502-510.

14. Arnlov J, Ingelsson E, Sundstrom J, Lind L: Impact of body mass index and the metabolic syndrome on the risk of cardiovascular disease and death in middle-aged men. Circulation 2010;121:230236.

15. Bazzano LA, Gu D, Whelton MR, Wu X, Chen CS, Duan X, Chen J, Chen JC, He J: Body mass index and risk of stroke among Chinese men and women. Ann Neurol 2010;67:11-20.

16. Yatsuya H, Yamagishi K, North KE, Brancati FL, Stevens J, Folsom AR: Associations of obesity measures with subtypes of ischemic stroke in the ARIC Study. J Epidemiol 2010;20:347-354. 